\title{
Compromiso ético y responsabilidad en el contexto universitario
}

\author{
Margarita Mauri-Álvarez \\ Universitat de Barcelona. España. https://orcid.org/0000-0003-4662-1454 \\ Correo para la correspondencia: mauri@ub.edu \\ Isabel Vilafranca-Manguán \\ Universitat de Barcelona. España. https://orcid.org/0000-0002-9362-7843 \\ Carles José-Mestre \\ Universitat de Barcelona. España. https://orcid.org/0000-0003-1681-1409
}

Artículo de Estudios y tendencias. Recibido: 22/10/2021. Aceptado: 27/10/2021. Publicación avanzada: 02/12/2021. Publicación: 03/01/2022.

\section{Resumen}

INTRODUCCIÓN. La situación excepcional de enseñanza virtual derivada de la crisis provocada por la pandemia causada por el COVID-19 abrió un debate universitario que pivotaba sobre el compromiso ético y la responsabilidad del estudiante a la hora de autentificar su identidad y autoría en la presentación de trabajos o evidencias evaluativas. El tema central era la responsabilidad individual y el compromiso ético del estudiante, dos competencias transversales comunes a muchos grados y másteres universitarios.

MÉTODO. El presente artículo trata de analizar, definir y dotar de contenido estas competencias desde la perspectiva de su adquisición por parte de estudiantes.

RESULTADOS. A la luz de esta aproximación conceptual, se ofrecen algunas pautas a los docentes universitarios para el fomento y enseñanza de las competencias mencionadas.

DISCUSIÓN. La función ejemplar del profesorado y de la institución universitaria, tal y como pretende demostrarse, resulta crucial para el fomento de la responsabilidad del estudiante y del compromiso ético.

\section{Palabras clave}

Compromiso ético, Responsabilidad, Educación superior, Profesorado universitario.

\section{Referencia recomendada}

Mauri-Álvarez, M., Vilafranca-Manguán, I., y José-Mestre, C. (2022). Compromiso ético y responsabilidad en el contexto universitario. REIRE Revista d'Innovació i Recerca en Educació, 15(1), 1-13. https://doi.org/10.1344/reire.36970

(C) 2021 Los autores. Este artículo es de acceso abierto sujeto a la licencia Reconocimiento 4.0 Internacional de Creative Commons, la cual permite utilizar, distribuir y reproducir por cualquier medio sin restricciones siempre que se cite adecuadamente la obra original. Para ver una copia de esta licencia, visite https://creativecommons.org/licenses/by/4.0/ 


\section{Títol (català)}

Compromís ètic i responsabilitat en el context universitari

\section{Resum}

INTRODUCCIÓ. La situació excepcional d'ensenyament virtual, derivada de la crisi provocada per la pandèmia de la covid-19, va obrir un debat universitari que pivotava sobre el compromís ètic i la responsabilitat de l'estudiant a l'hora d'autentificar la seva identitat i autoria en la presentació de treballs o activitats avaluatives. El tema central era la responsabilitat individual i el compromís ètic de l'estudiant, dues competències transversals comunes a molts graus i màsters universitaris.

MÈTODE. Aquest article mira d'analitzar, definir i dotar de contingut aquestes competències des de la perspectiva de la seva adquisició per part dels estudiants.

RESULTATS. A través d'aquesta aproximació conceptual, s'ofereixen algunes pautes als docents universitaris per fomentar i ensenyar les competències esmentades.

DISCUSSIÓ. La funció exemplar del professorat i de la institució universitària, tal com pretén demostrar-se, és crucial per al foment de la responsabilitat de l'estudiant i del compromís ètic.

Paraules clau

Compromís ètic, Responsabilitat, Educació superior, Professorat universitari.

\section{Title (English)}

Ethical commitment and responsibility in the university context

\section{Abstract}

INTRODUCTION. The exceptional situation of virtual education made necessary by the pandemic of COVID-19 opened up a university debate on students' ethical commitment and responsibility with regard to authenticating their identity and authorship when presenting their work for assessment. The central theme was individual responsibility and the ethical commitment of the student, two crosssectional competences common to many university degrees and master's degrees.

METHOD. This article aims to analyse, define and provide content for these competences from the perspective of their acquisition by students.

RESULTS. Applying this conceptual approach, a set of guidelines are offered to university teachers for promoting and teaching the two competences mentioned.

DISCUSSION. The paper aims to demonstrate that the exemplary role of the teaching staff and the university institution is crucial for promoting student responsibility and ethical commitment.

\section{Keywords}

Ethical commitment, Responsibility, Higher education, University teaching staff. 


\section{Introducción}

El advenimiento de la pandemia causada por el virus COVID-19, con el subsiguiente confinamiento ciudadano decretado con el estado de alarma a fin de evitar la transmisión, obligó a la docencia en línea. Este hecho inédito provocó la virtualización de la enseñanza, aprendizaje y evaluación en el contexto de las universidades presenciales, entre las cuales se sitúa la Universidad de Barcelona. Esa nueva situación abrió un debate que se centraba en el compromiso ético y la responsabilidad del estudiante a la hora de autentificar la autoría de los trabajos y/u otras evidencias evaluativas presentadas. Ante este desconocido escenario afloraron discusiones y debates que, si bien ya existían desde hacía tiempo, volvieron a tomar mucho protagonismo. La piedra angular de la cuestión era la responsabilidad individual y el compromiso ético del estudiante, dos competencias transversales comunes a todos los grados y másteres que se imparten en la Universidad de Barcelona. El presente artículo trata de analizar, definir y dotar de contenido sendas competencias desde la perspectiva de su adquisición por parte del estudiante, además de ofrecer algunas pautas a los docentes universitarios para el fomento y enseñanza de estas. Finalmente, se destaca la decisiva y trascendental función ejemplar del profesorado universitario para el fomento de la responsabilidad del estudiante y del compromiso ético.

\section{El contexto universitario}

Abordar un tema de esta naturaleza requiere, como conocimiento previo, que se realice una contextualización del entorno educativo en el que se analiza, a saber, la enseñanza superior universitaria. Cabe avanzar que son muchas las publicaciones que se han realizado sobre la responsabilidad social en la Universidad (Duque y Cervantes-Cervantes, 2019; Olarte-Mejía y Ríos-Osorio, 2015). No resulta, a todas luces, un tema nuevo. Nadie duda de la responsabilidad que tiene la Universidad en la formación para la ciudadanía en una sociedad democrática. Pero esta responsabilidad no se agota en el ámbito profesional o científico-técnico, sino que, además, ha de englobar el ámbito personal, así como el social. Sabido es que el tema de la formación ética, de la responsabilidad y de la educación para la ciudadanía en la institución universitaria no resulta nuevo, sino que, desde sus orígenes, la universidad ha estado comprometida con esta formación de sus estudiantes. De hecho, la formación ética, la responsabilidad y la ciudadanía forman parte de la propia idea de universidad. Se trata de un tipo de formación ya presente desde la instauración de las primeras universidades en Europa a lo largo de la Alta Edad Media. Los textos clásicos de referencia sobre la idea y misión de la universidad (Newman, 1852; Ortega y Gasset, 1930; Wyatt, 1990) así como los más próximos (Pelikan, 1992) se refieren a esta formación de una manera u otra.

En realidad, desde la implantación del Espacio Europeo de Educación Superior (EEES) esta cuestión ha vuelto a tener protagonismo en la agenda política universitaria. La puesta en marcha de este espacio puede ser concebida como la reconstrucción de una nueva universidad europea para un nuevo siglo (European University Association, 2005; 2010). El actual escenario concibe la formación universitaria en términos de competencias (European Council, 2007). Entre esas competencias se encuentran el carácter moral, ciudadano y la responsabilidad (González y Wagenaar, 2003). La Declaración de Roma, de 2017, aprobada por la UE, se comprometía a trabajar para conseguir una Unión en que los jóvenes recibieran la mejor educación y formación, además de que pudieran estudiar y encontrar trabajo en el continente, enfatizando el enfoque competencial transversal en todos los países que formaban parte de la Unión. La formación de la competencia ética y ciudadana, así como la responsabilidad en la universidad, se han convertido en un tema de máxima preocupación, incluso desde la política y la gestión universitaria (European Commission, 1995; OECD, 1997).

A lo largo de la historia de la formación ética y ciudadana en el ámbito universitario, en la universidad han convivido tres versiones contrapuestas. Una primera tendencia considera que la formación ética, ciudadana y la responsabilidad escapan de la misión y de la función prioritaria de la institución universitaria y, por tanto, aquella no tiene cabida en la Universidad. Entre las razones que se esgrimen para sostener esta postura se afirma que la formación universitaria se identifica con la formación profesional, técnica y científica. Este es su centro de atención, tanto que no hay espacio para otros tipos de formación en la universidad. No obstante, cabe apuntar 
que, en las primeras universidades de la Edad Media, sucedía lo contrario, a saber, la formación estaba totalmente centrada en la búsqueda de la Verdad, del Bien y de la Belleza (Berube, 2007; Rüegg, 1992). Atendiendo a estas consideraciones, esta versión presenta algunas debilidades. Además de perder el sentido fundacional de la institución universitaria, resulta que no hay garantías de que la formación ética, la responsabilidad y la formación para la ciudadanía finalicen con la educación previa a la formación universitaria. Quizás hoy en día, más que nunca, a causa del individualismo (Beck, 1992; Giddens, 1991) y el desinterés por las instituciones políticas y sociales de buena parte de la juventud (Duke, 2008; Forbrig, 2005; Saha et al., 2007), se requiere una universidad europea que apueste por la formación de jóvenes profesionales que se hagan cargo de la realidad desde la ética y la ciudadanía (Steiner, 2004). En contra de esta primera postura, reduccionista sobre el papel de la Universidad en el fomento del compromiso ético y ciudadano, Martínez y Esteban argumentan que «una formación universitaria de calidad no puede reducirse a una formación para la inserción laboral, por muy óptima que ésta pueda resultar» (Martínez y Esteban, 2005, p. 63).

Con relación al debate sobre la formación ética y ciudadana en la universidad, una segunda versión sostiene que la formación ética, la responsabilidad y la ciudadanía consisten esencialmente en la formación en los grandes asuntos éticos y ciudadanos que hoy en día nos interpelan. En este sentido, los estudiantes universitarios han de adquirir el desarrollo del razonamiento moral (Kohlberg, 1981; 1984). Temas como la justicia, la equidad, la sostenibilidad, la igualdad de género y la convivencia multicultural, serían algunos de los retos propios de esta forma de concebir la formación ética y ciudadana. No obstante, podríamos estar delante de una visión incompleta de la formación ética y de la responsabilidad. La realidad actual demuestra que, a pesar de que gran parte de los estudiantes asumen que se espera de ellos cierta altura moral, responsabilidad y ciudadanía, no siempre se consigue este reto (Moore, 2008; Procario-Foley y Bean, 2002).

Por último, una tercera tendencia es la que considera la formación ética y ciudadana en tanto que formación de un carácter de naturaleza moral (Lapsey y Clark, 2005; Nucci i Narváez, 2008), y, como tal, está centrada en la puesta en marcha de una serie de hábitos morales y de ciertas virtudes éticas. Esta tendencia, tal y como sugiere Michael Sandel: «No puede desprenderse del todo de la idea de que su papel no consiste solo en promover ciertos fines, sino también en honrar ciertas virtudes» (Sandel, 2011, p. 206).

De hecho, la virtud puede ser considerada de diversas formas, aunque uno de los autores que mejor conjuga las diferentes variantes históricas - a saber, la homérica, la aristotélica y la tomista-cristiana - es Alasdair Maclntyre, que la define como una «(...) cualidad humana adquirida, cuya posesión y ejercicio tiende a hacernos capaces de lograr aquellos bienes que son internos a las prácticas y cuya carencia nos impide efectivamente lograr cualquiera de tales bienes» (Maclntyre, 1984, pp. 270-271).

En este caso, la formación ética y ciudadana, así como la responsabilidad en la universidad, pueden ser concebidas como la conquista o logro de ciertas virtudes, que sin duda forman parte de una conducta buena. El rigor intelectual, la apreciación de voces autorizadas, la admiración por lo mejor que se ha dicho o el respeto hacia las maneras, entre otros, estarían entre ellas (Pérez Díaz, 2010).

Bajo este último paradigma, en la reciente resolución del Consejo de Europa (European Council, 2021) relativa al marco estratégico para la cooperación europea en el ámbito de la educación y la formación con miras al Espacio Europeo de Educación y más allá (2021-2030), publicada en el Diario Oficial de la Unión Europea, 26 de febrero de 2021, se destaca que la pandemia de la COVID-19 ha provocado una presión sin precedentes en el sector de la educación y la formación, derivando hacia una enseñanza y aprendizaje a distancia. Ante estos retos y oportunidades que se han abierto, vuelve a ser central el fomento de la competencia de la responsabilidad del estudiante y del compromiso ético, aspectos insoslayables para el crecimiento económico y las oportunidades de empleo, así como para el desarrollo personal, social y cultural de los países miembros. Aspectos y materias para las cuales la educación superior universitaria resulta indispensable.

A continuación se analizan el compromiso ético y el de responsabilidad, dos competencias fundamentales en la formación del estudiante universitario. 


\section{Compromiso ético}

La expresión "compromiso ético» es, en buena medida, redundante, dado que las razones que avalarían el cumplimiento de cualquier compromiso serían siempre de naturaleza moral. Ello se pone de manifiesto en las diferentes presentaciones que de la competencia pueden documentarse en textos institucionales, donde, por ejemplo, se la describe como capacidad crítica y autocrítica, y capacidad de mostrar actitudes coherentes con las concepciones éticas y deontológicas (Vicerectorat de Política Docent, 2008), o como competencia que ha de permitir al estudiante «actuar de manera honesta, ètica, sostenible, socialment responsable i respectuosa amb els drets humans i la diversitat, tant en la pràctica acadèmica com en la professional», al tiempo que «incorpora també la igualtat de gènere» (Doñate, 2020).

Las presentaciones de la competencia que se han escogido, sin embargo, serían notablemente representativas de un problema que institucionalmente no estaría bien resuelto, a saber, el esclarecimiento del tipo de obligación a que la competencia en cuestión apunta. Porque decir que el compromiso ético ha de consistir, entre otros logros, en la capacidad de mostrar actitudes coherentes con las concepciones éticas (Universitat de Barcelona), o en lo que ha de permitir al estudiante actuar de manera ética (Universitat Oberta de Catalunya), es incurrir en el error de incluir el definiendum en el definiens, de modo que se acaba ingresando un bucle teórico del cual no es fácil salir.

A la luz de lo apuntado, cabría preguntarse a qué pueden estar refiriéndose, por tanto, las mencionadas alusiones a la coherencia con la concepción ética, o a la capacidad de actuar de manera «ética». Se trataría de ajustar la conducta a unas normas que se desprenden de una determinada concepción ética, en el ámbito académico, por parte del estudiante. Una conducta integrada por actos al servicio de valores tales como la lealtad contractual o la igualdad de género, por ejemplo. Incluso se podría decir que, en ocasiones, se abre la puerta al cultivo de determinadas virtudes. ¿Cómo si no debería entenderse, por ejemplo, la llamada a la autocrítica (Vicerectorat de Política Docent, 2008), sin una implícita apelación a la virtud de la humildad? En todo caso, obsérvese que el alcance del compromiso ético por parte del estudiante pasaría indefectiblemente por demostrar, en todo momento, una adecuación práctica a unos determinados modelos morales, los cuales serían reflejo del previo ejercicio de ejemplaridad académica efectuado por parte de los integrantes de la institución.

En otro lugar definíamos el compromiso ético como la "capacidad de actuar con las virtudes personales y profesionales que requiere el correcto ejercicio de una profesión, el desarrollo personal y la ciudadanía democrática» (Esteban et al., 2018, p. 12). A la luz de esta definición, se puede afirmar que la formación universitaria tiene que ver con la formación del carácter moral del estudiante, así como con la adquisición de ciertas virtudes y cualidades humanas que permiten lograr determinados bienes. Así visto, la adquisición de la competencia compromiso ético, tal y como se ha planteado, exige que la argumentación moral se convierta en un hábito que se adquiera en la formación universitaria. De esta forma, el estudiante debe habituarse al razonamiento moral, a la búsqueda autónoma y razonada de determinados bienes y a los modos de alcanzarlos. Por este motivo, esta competencia no ha de formar parte únicamente de la formación universitaria, sino también ha de convertirse en el modo de vida universitario, una cualidad humana que ha de adquirirse y practicarse a lo largo de la formación universitaria.

Sin embargo, deberíamos analizar en qué se traduce la capacidad de actuar generada por la adquisición de la competencia "compromiso ético». A fin de sistematizar el compromiso ético se abordan las tres dimensiones en que puede dividirse. En primer lugar, en relación con uno mismo; en segundo, en relación con los demás y, en tercero y último, en relación con la institución universitaria. En el primero de los aspectos, el compromiso ético en relación con uno mismo, se podría decir que comprende: el comprometerse con el estudio y la adquisición de 
conocimientos, la voluntad y humildad de aprender, la implicación en el propio desarrollo moral y personal, el valor de enfrentarse a retos intelectuales, la perseverancia en el estudio y en los compromisos adquiridos, el esfuerzo y valor de auto-conducirse con criterio moral propio, la capacidad de reflexionar críticamente en relación con los contenidos, y la materia y la reflexión autocrítica sobre la propia conducta.

En lo que se refiere al compromiso ético con los demás es importante la veracidad del estudiante, la autenticidad, el respeto hacia posiciones diferentes de las demás personas, la búsqueda de la verdad a través del conocimiento y el diálogo argumentado, la capacidad de planificar conjuntamente las acciones y cumplir con los acuerdos, la escucha atenta y analítica de las argumentaciones del profesorado y de otros compañeros, la voluntad de compartir conocimientos y avanzar conjuntamente, y la humildad de dejarse acompañar en el proceso formativo, entre otras.

En lo que a la institución se refiere, conviene subrayar que la universidad es mucho más que un mero encuentro entre profesores y estudiantes. Por lo pronto, tiene ciertos ingredientes morales dado que incorpora la influencia personal y pedagógica de los docentes sobre sus alumnos. Se convierte así en una comunidad intelectual en la que todos los agentes implicados han de perseguir la excelencia, especulando sobre el conocimiento, interpretándolo, criticándolo e incluso imponiéndole un carácter prospectivo. En este sentido, la universidad es una comunidad moral. Entre los elementos que constituyen el compromiso ético en relación con la institución podríamos citar, entre otros, además del cuidado y respeto por los bienes inmuebles, la atenta escucha de las voces autorizadas, el esfuerzo por mejorar el entorno, la lectura crítica y atenta de la realidad y del conocimiento, y la prudencia intelectual. Estos podrían ser, entre otros muchos, algunos bienes que pueden adquirirse a través de la participación en determinadas prácticas y en la convivencia en la institución universitaria (Maclntyre, 1984).

Una vez pretendidamente esclarecida la esencia del compromiso ético como competencia que los estudiantes tienen que adquirir, cabe preguntarse si se puede/debe ir más allá de lo estrictamente práctico en relación con el proceso de comprobación de la adquisición de la competencia. El valor que está en juego en toda esta cuestión es el de la confianza, y nos ocuparemos específicamente de él en un apartado posterior, el dedicado a la peculiar relevancia actual de los conceptos de responsabilidad y compromiso ético a causa de la pandemia de COVID-19.

\section{Responsabilidad en el aprendizaje curricular}

La responsabilidad, tal como aparece definida en el diccionario de la RAE, es la "Capacidad existente en todo sujeto activo de derecho para reconocer y aceptar las consecuencias de un hecho realizado libremente». La responsabilidad es, pues, una capacidad, una cualidad que la persona posee por el hecho de ser racional. Sin embargo, atendiendo al hecho de que esta capacidad es posible que no pueda ejercerse por alguna deficiencia o por estar en alguna situación que la imposibilite, la capacidad de responsabilidad solo es atribuible a quién entiende qué está haciendo y, además, quiere hacer precisamente eso.

La responsabilidad de un agente se extiende a las consecuencias de su decisión, las consecuencias de su acto y también a las consecuencias de su actitud pues, tanto la decisión, el acto como la actitud están en poder del agente. La razón por la que alguien ha de responder de ellas - acto, decisión y actitud- radica en que aquel las ha tomado o realizado de forma consciente y libre, lo cual significa que el agente sabía y quería lo que estaba haciendo. En consecuencia, la capacidad de responder de lo que se ha elegido libremente exige del agente que reconozca y acepte las consecuencias que su actitud, decisión u acto hayan podido tener.

Las instancias ante las cuales una persona ha de responder son dos, la propia conciencia y, en un sentido vasto, la sociedad, puesto que ambas son las receptoras de las consecuencias de lo que se haya elegido. 
Con este marco de referencia se trata ahora de aplicar el concepto de "responsabilidad" al estudiante como agente en el contexto de los estudios universitarios que realiza.

La actividad que el estudiante lleva a cabo consiste en:
a) Asistir a clase.
b) Participar activamente en la clase.
c) Ser evaluado mediante exámenes, trabajos, exposiciones, etc.
d) Colaborar con los compañeros.
e) Relacionarse con los docentes.
f) El aprendizaje de contenidos a través del estudio.

Por otra parte, el lugar en el que el estudiante desarrolla su actividad comporta tanto la relación con el personal no docente como la relación con los elementos inmuebles.

Con respecto a la actividad y al lugar en que se desarrolla, el estudiante despliega actitudes, decisiones y actos de cuyas consecuencias debe responder ante sí mismo, ante la universidad y la sociedad.

¿A qué responsabilidades debe hacer frente el estudiante?

1. Asistir a clase.

2. Completar los conocimientos recibidos.

3. Propiciar un ambiente de trabajo en el aula.

4. Ser honesto en los trabajos que presenta y en los exámenes que realiza.

5. Responsabilidad sobre lo que cree, piensa y manifiesta.

6. Responsabilidad respecto a los compromisos que adquiere.

7. Es responsable de las metas que se marca.

Para asumir estas responsabilidades son necesarias cuatro condiciones:

1. Realismo.

2. Autoconocimiento.

3. Humildad.

4. Respeto por los demás - compañeros, profesores, personal no docente e institución.

La cualidad de realismo supone que el alumno tiene un conocimiento de las exigencias del contexto en el que se desarrolla su actividad, de sus propias capacidades y de su tiempo. Poniendo en relación estos tres elementos, una actitud realista ajusta las posibilidades personales y el tiempo a las exigencias. Adquirir compromisos cuando no se dispone de tiempo, por ejemplo, es considerado una actitud irresponsable. La falta de realismo revierte en el incumplimiento de lo que se espera de un estudiante y en la frustración del propio estudiante. Las responsabilidades aceptadas, que se espera cumpla el estudiante, deben estar de acuerdo con las posibilidades reales que aquel tenga. La tendencia tan extendida hoy de suponer que no existen límites a las posibilidades intelectuales, de tiempo, o de dedicación tiende a crear en los estudiantes la falsa idea de que todo es posible.

El autoconocimiento es una condición indispensable de la actitud realista. El conocimiento de uno mismo abarca tanto el de las propias capacidades como el de los deseos, y no es nada fácil saber lo que uno realmente quiere. La convicción de estar cursando los estudios que se desean es clave para el compromiso y asunción de las distintas responsabilidades. El autoconocimiento y la apertura a la realidad circundante tienen que abocar en una actitud humilde. Solo el convencimiento de que el estudiante puede aprender de los que le rodean dará paso a que se tome seriamente su actividad en la universidad y las responsabilidades que esa actividad comporta: «(...) la humildad, escribe Iris Murdoch, no es un hábito peculiar de autoanulación, algo así como tener una voz inaudible, 
es el respeto desinteresado por la realidad y una de las más difíciles y centrales de todas las virtudes» (Murdoch, 2001, p. 98). La disposición humilde se manifiesta en una actitud de respeto hacia los demás y la consecuencia de ese respeto es la asunción de las responsabilidades propias del estudiante.

Las reflexiones que se han ofrecido con respecto a la responsabilidad del estudiante universitario en el ejercicio de su actividad pueden ser consideradas desde la perspectiva de cómo puede contribuir la universidad a su desarrollo. En el caso de las responsabilidades a las que se ha hecho referencia, la labor del profesor resulta fundamental. Con su actitud, el profesor puede coadyuvar a que el alumno tome conciencia de que ha de ser el protagonista real de las responsabilidades que le competen. La creación de un buen ambiente de aprendizaje y de una buena intercomunicación entre los alumnos puede favorecer el ejercicio de la responsabilidad individual. Por otra parte, es innegable que el ejemplo del profesor tiene un eco, consciente o no, en el aprendizaje de los alumnos. Una de las mejores formas de favorecer el desarrollo de la responsabilidad en los alumnos es que el profesor sea responsable en todos los ámbitos que su actividad comporte. Es a través del profesor como, de un modo directo, la institución se hace presente al alumno. A menudo, la opinión que la universidad merece por parte de sus alumnos es debida al ejemplo que los docentes ofrecen. En este sentido, M.L. McBee (1978) afirma que la universidad ha de ser un ejemplo de conducta noble, y esta puede mostrarse de diversas formas:

1. En la forma democrática con que los órganos competentes gobiernan.

2. En la profesionalidad de los docentes.

3. En la honestidad con que los miembros de la universidad realizan la investigación.

4. En el modo como se trata a las minorías en la universidad.

5. En el control de la calidad de la docencia y del trabajo de los estudiantes.

6. En la atención a la igualdad y a la excelencia, sin sacrificar ninguno de los dos criterios.

Desde la tarea individual que cada profesor desarrolla o desde el conjunto de la institución, lo que sus agentes hacen tiene una repercusión, positiva o negativa, en los estudiantes. Con ello no se afirma que la universidad sea totalmente responsable del desarrollo en los alumnos de la competencia de responsabilidad, pero sí que de las actuaciones individuales de los profesores y de la institución derivan modelos de conducta que promueven o truncan el fortalecimiento de esa responsabilidad.

\section{La función ejemplar del docente en el fomento de estas competencias}

Como se ha visto en las páginas previas, la universidad como institución se halla fuertemente comprometida con la sociedad y con el sistema democrático en los que se circunscribe y a quienes debe rendir cuentas. Como tal, la universidad no puede desprenderse de un cierto compromiso con la obligación de fomentar actitudes, valores, hábitos y competencias que vayan en esta dirección. Tal es el caso concreto de las competencias tratadas a lo largo de este escrito, a saber, la responsabilidad individual y el compromiso ético. En cualquier caso, el fomento de estas competencias es una obligación de la institución universitaria.

Ahora bien, la responsabilidad individual del estudiante no surge si no es por la ejemplaridad manifiesta del profesorado y de la institución. De hecho, es más difícil desarrollar la responsabilidad como estudiante y el compromiso ético en un medio en que la dejadez, la desidia, el incumplimiento de normas, la falta de respeto por los demás y por el entorno son conductas y hábitos generalizados, y no una excepción. A decir verdad, en un ambiente de estas características es difícil que estas competencias se desarrollen. Dicho en otras palabras, tanto la institución como sus profesores han de mostrar una actitud ejemplar. Poner en el centro la responsabilidad del alumno y su compromiso ético requiere que el espejo en el que se refleje -institución docente y profesoradoactúen de forma honesta, comprometida y responsable en relación con sus funciones.

Con anterioridad, se afirmaba que, para el cumplimiento de sus responsabilidades, en el estudiante se han de dar cuatro condiciones: realismo, autoconocimiento, humildad y respeto por los demás. Resulta coherente, desde este punto de vista, exigir también al profesorado y a la institución estas cuatro condiciones. En esta dirección, 
Martínez y Carreño afirman que el compromiso ético del profesorado universitario tiene tres dimensiones (Martínez y Carreño, 2020, p. 8). Cabe apuntar que estas tres dimensiones también serían extrapolables a la competencia de la responsabilidad, tal y como intentaremos desarrollar seguidamente. La primera dimensión está relacionada con la calidad de los aprendizajes, la segunda con la identidad personal y profesional que promueve en los futuros profesionales y la tercera con la formación de estos. En relación con esta última, esta

obliga al profesorado universitario a practicar con el ejemplo tanto en la manera de ejercer la docencia como en las maneras de promover el aprendizaje de sus estudiantes y de relacionarse con ellos en los espacios formales e informales de la vida universitaria. (Martínez y Carreño, 2020, p. 8)

Por lo que respecta a la primera dimensión, la relacionada con la calidad de los aprendizajes, se intentará, a continuación, concretarla y dotarla de contenido en el terreno de la responsabilidad y el compromiso ético del profesorado. De este modo, y vinculado con las condiciones de la responsabilidad, el profesorado ha de ser realista y humilde en la calidad de los aprendizajes que propicia en los estudiantes. A saber, ha de comprometerse fuertemente con los objetivos de su docencia y la programación de sus materias, preparándolas con ilusión, pero también con exhaustividad y realismo, acotando bien los contenidos esenciales y fomentando actividades con que se ayude a los estudiantes a asumirlos. No resulta extraño que se requiera de una buena y contundente preparación previa, tanto de los contenidos de la asignatura como de las actividades con las que fomentará el aprendizaje de los alumnos. Aspectos esenciales para el buen desarrollo de la asignatura y del proceso de enseñanza-aprendizaje. Esto implica, a su vez, no sólo la impartición y transmisión de la materia, sino una buena programación de las actividades evaluativas con las que se comprobará el grado de adquisición de esta.

Respetar a los demás, otra de las condiciones de la responsabilidad del estudiante, se traduce, por parte del profesor, en respetar a los alumnos, sus aportaciones, sus argumentaciones y acompañarlos de forma continuada, leyendo bien los trabajos, exámenes y otras evidencias evaluativas y retornando las tareas a los alumnos en un tiempo prudencial y con anotaciones que les permitan conocer y mejorar su proceso de aprendizaje y la calidad del documento presentado. Cuando el profesor se compromete en estas acciones, cumple con los plazos establecidos, compromete, en cierto modo, al alumno a desarrollar también su responsabilidad como estudiante - tanto en la entrega de trabajos como en la elaboración propia de los mismos. En definitiva, si el alumno siente que su aportación ha sido respetada por el docente, aumenta la probabilidad de que cuide más lo que presenta y se responsabilice de ello, respetando, a su vez, la labor del profesorado y de los demás. Por consiguiente, entre otros, el docente ha de ser humilde y realista tanto sobre lo que puede exigir como trabajo de materia como acerca de lo que debe responder en las correcciones de las entregas de los alumnos.

Otra de las dimensiones de este compromiso a la que se refieren Martínez y Carreño es al de la identidad personal y profesional que se promueve en los futuros profesionales. Aquí entrarían en juego el rigor moral personal y el compromiso ético profesional, en relación con condiciones como el autoconocimiento, la humildad y el realismo. De forma responsable, el profesor ha de tener el autoconocimiento y la humildad necesaria, tanto en lo que a sus limitaciones personales y profesionales se refiere como a lo que sabe o no sabe; en lo que, aun no sabiéndolo, puede aprender y en lo que aun sabiéndolo o conociéndolo pudiera estar equivocado, dada la falibilidad del conocimiento. Además, pues, de conocer en profundidad el ámbito o área de conocimiento en la que su docencia se sitúa, ha de estar abierto y atento a nuevas incorporaciones y avances científico-técnicos de su materia.

De nuevo aquí, la honestidad del profesor juega un papel crucial. Se sabe lo que se sabe, pero, además, se ha de saber que es necesario seguir aprendiendo, estudiando e investigando de forma continuada. Frente a la voluntad de que alumno amplíe sus conocimientos, se requiere la humildad, por parte del profesorado, de hacerlo también de forma constante. El profesor ha de ofrecer en el aula documentos, bibliografía de ampliación y consolidación, material complementario y artículos que permitan al alumno afianzar o profundizar en el contenido de la asignatura. Dentro de los compromisos docentes está el de mantener la bibliografía actualizada, el de ofrecer otras vías alternativas de adquisición de contenidos, desde la humildad que se demuestra al admitir que no se sabe ni se conoce todo, siempre que se esté dispuesto a seguir aprendiendo y esforzándose en seguir estudiando o investigando. 
En otro orden de cosas, según Martínez y Carreño, la última de las dimensiones del compromiso ético está vinculada a la formación de los estudiantes. Se afirmaba con anterioridad que una de las dimensiones de la responsabilidad a que ha de hacer frente el estudiante es a la de ser responsable sobre lo que cree, piensa y manifiesta. Resulta evidente que el docente, para que así sea, ha de ofrecer espacios de crecimiento y maduración intelectual y personal del alumno, actividades de debate y discusión oportunos sobre los contenidos de la materia, siempre que la naturaleza de la misma lo permita. A través de diferentes actividades, seminarios monográficos o diálogos argumentados sobre lecturas o dilemas de la asignatura, el profesor ha de procurar que los estudiantes elaboren su propia argumentación, razonen sus respuestas o posiciones y que las apoyen en argumentos sólidos que demuestren su conocimiento de la materia. No se trata de fomentar la opinión. Todo lo contrario. Se ha de procurar que los estudiantes aprendan a realizar análisis críticos de las situaciones y de los dilemas morales a los que se enfrentan como estudiantes y a los que puedan enfrentarse en un futuro profesional. Conformar la identidad personal y profesional es un reto con el que los docentes han de comprometerse.

Según lo dicho, es necesario que el profesor no improvise su docencia de forma constante. Consciente de que siempre existe un cierto grado de incertidumbre en la programación, esto no exime al profesor de preparase bien la materia, los contenidos y programar con cierta exhaustividad - abierto a posibles momentos de espontaneidad o imprevistos propios de la naturaleza de cualquier proceso de enseñanza-aprendizaje- la docencia y evaluación de esta, así como las actividades de aprendizaje.

Para la conformación de estas tres dimensiones, deberíamos analizar, más allá de lo dicho, qué condiciones debería cumplir un profesor para ejercer esa labor ejemplar a la que se hacía referencia. De entrada, cabe reiterar que en su quehacer diario el profesor ha de ser un ejemplo. Podrían subrayarse, como condiciones profesionales del docente la veracidad, el compromiso con la investigación de excelencia en su ámbito y la formación continuada en el área de conocimiento, la honestidad en sus investigaciones, labores docentes y publicaciones y el compromiso con la democracia universitaria y la gestión de la institución.

Claro está que la veracidad es condición indispensable de la excelencia docente. La veracidad es, como tal,

la capacidad comunicativa humana bajo el supuesto de que el ser humano puede conocer lo que llamamos como "realidad". Para definir la virtud de la veracidad son necesarios tres elementos: el emisor veraz, y todo lo que comporta, el receptor al que se comunica la verdad y la realidad objeto del conocimiento verdadero comunicado. (Esteban et al., 2018, pp. 28-29)

A este respecto, la veracidad implica un compromiso con el otro, alteridad, y con la realidad que envuelve al agente moral.

Esta definición implica directamente la siguiente condición, a saber, el compromiso con la investigación de excelencia en su ámbito y la formación continuada en el área de conocimiento. Efectivamente, un docente veraz ha de perseguir la búsqueda de la verdad sobre la parte de la realidad a la que atiende su área de conocimiento o disciplina. Por este motivo, ha de comprometerse necesariamente con la excelencia en su investigación, y, como no, con la necesaria formación continuada en su ámbito científico-técnico, aspecto esencial de la excelencia investigadora. De aquí deriva, también, la honestidad en sus investigaciones, labores docentes y publicaciones. Honestidad en el sentido de actuar rectamente, buscando determinados bienes y desplegando sus acciones en consecuencia.

Por último, otra de las condiciones señaladas es el compromiso con la democracia universitaria y la gestión de la institución. El docente, como tal, participa de una institución que tiene sus normas y modos de funcionamiento. En general, estos órganos son democráticos y están constituidos por personas que representan los diferentes colectivos docentes, personal no académico y alumnado. El profesorado ha de comprometerse y participar activamente en los procedimientos democráticos de esta gestión y las decisiones que en estos órganos se toman. En última instancia, resultaría incoherente que se pretendiera educar para la ciudadanía democrática si no se participa en los órganos democráticos de la institución de la que se forma parte, a saber, en la universidad. 
Como se ha dicho, para que el alumno cumpla con sus responsabilidades se requiere de cuatro condiciones: realismo, autoconocimiento, humildad y respeto por los demás. Resulta coherente exigir también al profesorado y a la institución estas cuatro condiciones.

\section{Conclusiones. Relevancia del compromiso ético y responsabilidad en la actualidad}

Como se apuntaba a lo largo de las líneas precedentes, la pandemia de COVID-19 ha impactado notablemente en el planteamiento pedagógico y organizativo de la Universidad presencial. Más allá de la obligada adaptación coyuntural a la situación sobrevenida, dicha institución se ha visto compelida a repensar los métodos de enseñanza/aprendizaje y evaluación instaurados a partir del EEES, en particular para con su concreta puesta en práctica. Así, se ha evidenciado que los modelos presencial y no-presencial no son conjuntos disjuntos, y que estrategias clásicas de la no-presencialidad pueden incorporarse a la docencia presencial si el docente considera que ello optimizará el rendimiento del alumno y su aprovechamiento de las asignaturas.

La parte oculta del nuevo escenario hace precisamente referencia a los conceptos clave aquí estudiados: compromiso ético y responsabilidad. Es evidente, y las universidades han tenido constancia de diferentes casos, que la docencia y evaluación exclusivamente en línea o a distancia ha presentado lagunas en cuanto a delicados asuntos como la autenticación, la autoría y la intransferibilidad. En la medida en que se preserven, pues, prácticas y hábitos académicos adoptados durante la situación de excepcionalidad, los supuestos problemas que dichas prácticas y hábitos acarreen no desaparecerán. En particular, el compromiso ético será especialmente relevante en contextos anónimos, mientras que la responsabilidad se tornará decisiva en procesos de autoevaluación y rendimiento de cuentas.

A modo de conclusión, podríamos recordar la acertada expresión de Victoria Camps cuando afirma que la educación navega constantemente contracorriente. Contra una corriente dominante que, de acabar imponiéndose, podría llegar a corromper y desviar la condición humana (Camps, 2008). Bien mirado, la formación universitaria no queda al margen de esta navegación. Ciertamente, ante la situación actual, la forzada formación en línea de la universidad clásicamente presencial, a la que se aludía previamente, resulta más importante, si cabe, fomentar la responsabilidad individual y el compromiso ético del alumnado. Después de todo, se trata de combatir, mediante la educación, las conductas insolidarias y la falta de responsabilidad. Precisamente en esta dirección apuntan las dos competencias tratadas, la responsabilidad del estudiante y el compromiso ético.

\section{Organismo colaborador}

Los resultados de esta investigación se enmarcan en el proyecto "La responsabilitat de l'estudiant: abast i límits" (código del proyecto REDICE20-2680) cuya financiación fue aprobada por el IDP-ICE UB. El proyecto fue concedido al Grupo consolidado de innovación docente GIDÈTICA, del cual son miembros los firmantes de este artículo.

\section{Referencias}

Beck, U. (1992). Risk Society. Towards a New Modernity: Theory, Culture and Society. Sage.

Berube, M. (2007). What's Liberal about the Liberal Arts? W.W. Norton.

Camps, V. (2008). Creure en l'educació. L'assignatura pendent. Edicions 62. 
Doñate, A. (2020, 11 de febrero). La UOC incorpora el compromiso ético y global en sus grados y másteres. Actualitat.

https://www.uoc.edu/portal/es/news/actualitat/2020/135-competencia-etica-global.html

Duke, C. (2008). University Engagement: Avoidable Confusion and Inescapable Contradiction. Higher Education Management and Policy, 20, 1-11. https://doi.org/10.1787/hemp-v20-art12-en

Duque, P., y Cervantes-Cervantes, L. (2019). Responsabilidad social universitaria: una revisión sistemática y análisis bibliométrico. Estudios Gerenciales, 35(153), 451-464.

https://doi.org/10.18046/j.estger.2019.153.3389

Esteban, F., Mauri, M., Román, B., y Vilafranca, I. (2018). El compromiso ético en la formación universitaria: reflexiones y recomendaciones. ICE-Octaedro.

European Commission (1995). White Paper on Education and Training. Teaching and Learning: Towards the Learning Society. COM (95) 590. European Commission.

European Council (2007). On the New Skills for New Jobs. Official Journal of the European Union. 2007/C 290/01. European Commission.

http://www.eurlex.europa.eu/LexUriServ/LexUriServ.do?uri=OJ:C:2007:290:0001:0003:EN:PDF

European Council (2021). Resolución del Consejo relativa a un marco estratégico para la cooperación europea en el ámbito de la educación y la formación con miras al Espacio Europeo de Educación y más allá (20212030) (2021/C 66/01).

https://eur-lex.europa.eu/legal-content/ES/TXT/PDF/?uri=CELEX:32021G0226(01)\&from=ES

European University Association (2005). Trends IV: European Universities Implementing Bologna. EUA. https://eua.eu/resources/publications/390:trends-2005-european-universities-implementingbologna\%C2\%A0.html

European University Association (2010). Trends VI: A Decade of Change in European Higher Education Area. EUA. https://eua.eu/resources/publications/312:trends-2010-a-decade-of-change-in-european-highereducation.html

Forbrig, J. (ed.) (2005). Revisiting Youth Political Participation. Council of Europe Publishing.

Giddens, A. (1991). Modernity and Self-Identity: Self and Society in the Late Modern Age. Polity.

González, J., y Wagenaar, R. (eds.). (2003). Tuning Educational Structures in Europe. Final Report. Phase One. Universidad de Deusto.

Kohlberg, L. (1981). The Meaning and Measurement of Moral Development. Clark University Press.

Kohlberg, L. (1984). Essays on Moral Development. The Psychology Moral Development. Jossey Bass.

Lapsley, D., y Clark, F. (2005). Character Psychology and Character Education. University of Notre Dame Press.

MacIntyre, A. (1984). Tras la virtud. Editorial Crítica. 
Martínez, M., y Carreño, P. (2020). El compromiso ético del profesorado universitario en la formación de docentes. Profesorado. Revista de currículum y formación del profesorado, 24(2), 8-26. https://doi.org/10.30827/profesorado.v24i2.15150

Martínez, M., y Esteban, F. (2005). Una propuesta de formación ciudadana para el EEES. Revista Española de Pedagogía, 230, 63-84.

McBEE, M. L. (1978). Higher Education: Its Responsibility for Moral Development. National Forum: Phi Kappa Phi Journal, 58, 30-33.

Moore, S. (2008) Practical Approaches to Ethics for Colleges and Universities. Jossey-Bass.

Murdoch, I. (2001). La soberanía del bien. Caparrós Editores.

Newman, J. H. (1852). The Idea of a University. Longmans Green \& Co, 1927.

Nucci, L., y Narváez, D. (2008). Handbook of Moral and Character Education. Routledge. https://doi.org/10.4324/9780203931431

OECD (1997). DeSeCo Project. Definition and Selection of Competencies: Theoretical and Conceptual Foundations. OECD.

Olarte-Mejía, D. V., y Ríos-Osorio, L. A. (2015). Enfoques y estrategias de responsabilidad social implementadas en Instituciones de Educación Superior. Una revisión sistemática de la literatura científica en los últimos 10 años. Revista de la Educación Superior, 44(175), 19-40. https://doi.org/10.1016/j.resu.2015.10.001

Ortega y Gasset, J. (1930). La misión de la universidad. Alianza Editorial.

Pelikan, J. (1992). The Idea of the University: A Re-examination. Yale University Press.

Pérez-Díaz, V. (2010). Universidad, Ciudadanos y nómadas. Ediciones Nobel.

Procario-Foley, E., y Bean, D. (2002). Institutions of Higher Education: Cornerstones in Building Ethical Organizations. Teaching Business Ethics, 6, 101-116. https://doi.org/10.1023/A:1014214909390

Rüegg, W. (1992). A History of the University in Europe. Cambridge University Press.

Saha, J. L., Print, M., y Edwards, K. (eds.) (2007). Youth and Political Participation. Sense Publishers. https://doi.org/10.1163/9789087904470

Sandel, M. (2011). Justicia. ¿Hacemos lo que debemos? Random House Mondadori.

Steiner, G. (2004). The Idea of Europe. Uitgeverij Nexus.

Vicerectorat de Política Docent (2008). Competències transversals de la Universitat de Barcelona. Publicacions i edicions de la Universitat de Barcelona.

Wyatt, J. (1990). Commitment to Higher Education. Seven West European Thinkers on the Essence of the University. Max Horkeimer, Karl Jaspers, F.R. Leavis, John Herny Newman, José Ortega y Gasset, Paul Tillich, Miguel de Unamuno. SHRE and Open University Press. 